\title{
Neuropsychopharmacology of psychosis: relation of brain signals, cognition, and chemistry
}

\section{André Schmidt* and Stefan Borgwardt}

Department of Psychiatry (UPK), University of Basel, Basel, Switzerland

${ }^{*}$ Correspondence: andre.schmidt@unibas.ch

Edited and reviewed by:

Mihaly Hajos, Yale University School of Medicine, USA

Keywords: psychosis, psychosis high-risk state, cognition, neuroimaging, pharmacology, computational psychiatry, brain connectivity

Recent research has resumed the pivotal significance of cognitive impairments for the development of psychosis spectrum disorders, proposing a shift in focus extending from psychotic symptoms as the key hallmarks $(1,2)$. Cognitive deficits are of particular interest as they precede the onset of psychosis by many years in the absence of any psychotic symptom and thus providing valuable predictions about the longitudinal course (3). Recognizing cognitive disturbances as the main promoter may allow early detection of the illness and might also lead to adequate and effective treatment.

Neuroscientific brain imaging techniques have essentially helped putting the attention back on cognition. In this research topic, we aimed at emphasizing the tremendous relevance of cognitive impairments for the early stages of psychosis and their neurobiological correlates as measured with a broad variety of brain imaging modalities such as electro- and magnetoencephalography, structural, functional, and resting state magnetic resonance imaging, near-infrared spectroscopy, and proton magnetic resonance spectroscopy. The topic begins with articles emphasizing the evidence of cognitive deficits in patients with schizophrenia, first-episode psychosis, and in persons from the general population with psychosis-like experiences and whether they are mirrored in brain signals as measured by functional near-infrared spectroscopy or structural magnetic resonance imaging (4-7). Further works review the underlying neuropharmacological mechanisms of cognitive impairments by focusing on different established domains and discuss potential drug targets for cognitive enhancement treatments $(8,9)$. This research topic also highlights the significance of the $N$-methyl-D-aspartate receptor for the development of psychosis and how glutamatergic metabolites are related to symptoms and cognitive function in clinical samples, suggesting promising new target pathways for the treatment of psychosis (10-12). Furthermore, electrophysiological modeling strategies in animals (13) and healthy subjects (14-16) are presented, which might help to establish neurobiological markers not only for the treatment of cognitive deficits but also for the prediction of psychosis and the development of preventive treatment schemes. The largest part of this issue unifies theoretical and experimental evidence reflecting the immense potential of computational neuroscience for shedding new light on the neurophysiological mechanisms underlying psychosis in general and on the formation of specific psychopathological signs and symptoms in particular. It starts with a normative consideration of psychotic symptoms as a result of aberrant encoding of precision embedded with predictive coding framework (17). The topic ends up with several computational modeling approaches and reviews addressing the relation between neural network properties, pharmacological challenges, cognition, and genetic risk (18-22).

This issue is intended to provide a state-of-the-art cognitive perspective to consider developing psychosis and will serve as useful framework for further investigations inferring pathophysiological mechanisms of psychosis. Such sorts of analyses might help to predate the onset of psychosis in terms of abnormal brain signals and to improve and develop new therapeutic scenarios. We would like to thank all the authors and reviewers for their valuable contributions, as well as the Editorial Office for their help in the editing process.

\section{REFERENCES}

1. Fusar-Poli P, Borgwardt S, Bechdolf A, Addington J, Riecher-Rössler A, SchultzeLutter F, et al. The psychosis high-risk state: a comprehensive state-of-theart review. JAMA Psychiatry (2013) 70(1):107-20. doi:10.1001/jamapsychiatry. 2013.269

2. Schmidt A, Smieskova R, Aston J, Simon A, Allen P, Fusar-Poli P, et al. Brain connectivity abnormalities predating the onset of psychosis: correlation with the effect of medication. JAMA Psychiatry (2013) 70(9):903-12. doi:10.1001/jamapsychiatry.2013.117

3. Fusar-Poli P, Deste G, Smieskova R, Barlati S, Yung A, Howes O, et al. Cognitive functioning in prodromal psychosis: a meta-analysis cognitive functioning in prodromal psychosis. Arch Gen Psychiatry (2012) 69(6):562-71. doi:10.1001/archgenpsychiatry.2011.1592

4. Kuswanto CN, Sum MY, Sim K. Neurocognitive functioning in schizophrenia and bipolar disorder: clarifying concepts of diagnostic dichotomy vs. continuum. Front Psychiatry (2013) 4:162. doi:10.3389/fpsyt.2013.00162

5. Ayesa-Arriola R, Roiz-Santiáñez R, Pérez-Iglesias R, Ferro A, Sainz J, CrespoFacorro B. Neuroanatomical differences between first-episode psychosis patients with and without neurocognitive deficit: a 3-year longitudinal study. Front Psychiatry (2013) 4:134. doi:10.3389/fpsyt.2013.00134

6. Ziermans TB. Working memory capacity and psychotic-like experiences in a general population sample of adolescents and young adults. Front Psychiatry (2013) 4:161. doi:10.3389/fpsyt.2013.00161

7. Koike S, Nishimura Y, Takizawa R, Yahata N, Kasai K. Near-infrared spectroscopy in schizophrenia: a possible biomarker for predicting clinical outcome and treatment response. Front Psychiatry (2013) 4:145. doi:10.3389/fpsyt.2013.00145

8. Kroken RA, Løberg EM, Drønen T, Grüner R, Hugdahl K, Kompus K, et al. A critical review of pro-cognitive drug targets in psychosis: convergence on myelination and inflammation. Front Psychiatry (2014) 5:11. doi:10.3389/fpsyt.2014. 00011

9. Vingerhoets WA, Bloemen OJ, Bakker G, van Amelsvoort TA. Pharmacological interventions for the MATRICS cognitive domains in schizophrenia: what's the evidence? Front Psychiatry (2013) 4:157. doi:10.3389/fpsyt.2013.00157 
10. Merritt K, McGuire P, Egerton A. Relationship between glutamate dysfunction and symptoms and cognitive function in psychosis. Front Psychiatry (2013) 4:151. doi:10.3389/fpsyt.2013.00151

11. Lakhan SE, Caro M, Hadzimichalis N. NMDA receptor activity in neuropsychiatric disorders. Front Psychiatry (2013) 4:52. doi:10.3389/fpsyt. 2013.00052

12. Gruber O, Chadha Santuccione A, Aach H. Magnetic resonance imaging in studying schizophrenia, negative symptoms, and the glutamate system. Front Psychiatry (2014) 5:32. doi:10.3389/fpsyt.2014.00032

13. Lee H, Dvorak D, Fenton AA. Targeting neural synchrony deficits is sufficient to improve cognition in a schizophrenia-related neurodevelopmental model. Front Psychiatry (2014) 5:15. doi:10.3389/fpsyt.2014.00015

14. Todd J, Harms L, Schall U, Michie PT. Mismatch negativity: translating the potential. Front Psychiatry (2013) 4:171. doi:10.3389/fpsyt.2013.00171

15. Bodatsch M, Klosterkötter J, Daumann J. Contributions of experimental psychiatry to research on the psychosis prodrome. Front Psychiatry (2013) 4:170. doi:10.3389/fpsyt.2013.00170

16. Mathalon DH, Ahn KH, Perry EB, Cho HS, Roach BJ, Blais RK, et al. Effects of nicotine on the neurophysiological and behavioral effects of ketamine in humans. Front Psychiatry (2014) 5:3. doi:10.3389/fpsyt.2014.00003

17. Adams RA, Stephan KE, Brown HR, Frith CD, Friston KJ. The computational anatomy of psychosis. Front Psychiatry (2013) 4:47. doi:10.3389/fpsyt.2013. 00047

18. Dauvermann MR, Whalley HC, Schmidt A, Lee GL, Romaniuk L, Roberts N, et al. Computational neuropsychiatry - schizophrenia as a cognitive brain network disorder. Front Psychiatry (2014) 5:30. doi:10.3389/fpsyt.2014. 00030

19. Anticevic A, Cole MW, Repovs G, Savic A, Driesen NR, Yang G, et al. Connectivity, pharmacology, and computation: toward a mechanistic understanding of neural system dysfunction in schizophrenia. Front Psychiatry (2013) 4:169. doi:10.3389/fpsyt.2013.00169

20. Deserno L, Boehme R, Heinz A, Schlagenhauf F. Reinforcement learning and dopamine in schizophrenia: dimensions of symptoms or specific features of a disease group? Front Psychiatry (2013) 4:172. doi:10.3389/fpsyt.2013.00172

21. Roiser JP, Wigton R, Kilner JM, Mendez MA, Hon N, Friston KJ, et al. Dysconnectivity in the frontoparietal attention network in schizophrenia. Front Psychiatry (2013) 4:176. doi:10.3389/fpsyt.2013.00176

22. Diwadkar V, Bakshi N, Gupta G, Pruitt P, White R, Eickhoff S. Dysfunction and dysconnection in cortical-striatal networks during sustained attention: genetic risk for schizophrenia or bipolar disorder and its impact on brain network function. Front Psychiatry (2014) 5:50. doi:10.3389/fpsyt.2014.00050

Conflict of Interest Statement: The authors declare that the research was conducted in the absence of any commercial or financial relationships that could be construed as a potential conflict of interest.

Received: 19 May 2014; accepted: 13 June 2014; published online: 01 July 2014.

Citation: Schmidt A and Borgwardt S (2014) Neuropsychopharmacology of psychosis: relation of brain signals, cognition, and chemistry. Front. Psychiatry 5:76. doi: 10.3389/fpsyt.2014.00076

This article was submitted to Schizophrenia, a section of the journal Frontiers in Psychiatry.

Copyright (c) 2014 Schmidt and Borgwardt. This is an open-access article distributed under the terms of the Creative Commons Attribution License (CC BY). The use, distribution or reproduction in other forums is permitted, provided the original author(s) or licensor are credited and that the original publication in this journal is cited, in accordance with accepted academic practice. No use, distribution or reproduction is permitted which does not comply with these terms. 